\title{
Discourse Analysis of Shopee “12.12. Birthday Sale” Advertisement
}

\author{
Novia Diah Lestari \\ Gunadarma University, Jl. Salemba Raya No. 53 Jakarta Pusat, Indonesia
}

\begin{abstract}
This article aims at finding out the purpose of why this advertisement is made and the social conditions underlying the making of the advertisement. This article applies a descriptive qualitative method in which, the method describes and explains the phenomenon or events in the social world. In this article, the writer uses the threedimensional theory of discourse analysis proposed by Fairclough (1995) and the connotative meaning of color proposed by Wilfred (1962). Based on the analysis, it is found that the purpose of this advertisement is to introduce the products and brands of the advertiser to the society, as well as to advertise their identity as a company which follows the trend and comply with the consumer wishes. The social conditions behind the making of the advertisements are; first, the increasing level of consumer consumption; second, the existence of national online shopping events in Indonesia; and the fondness of Indonesian people towards Korean music and culture, which makes the advertiser chooses to make Korean artist as the model of the advertisement.
\end{abstract}

Keywords: discourse analysis, advertising discourse, Fairclough's three-dimensional theory

DOI: $10.7176 / \mathrm{JLLL} / 69-05$

Publication date:June 30th 2020

\section{Introduction}

Advertising is a medium to promote and introduce a product to the community. As quoted by Dyer (2009), "In its simplest sense the word 'advertising' means 'drawing attention to something', or notifying or informing somebody of something” (p.2). It means that advertising aims at attracting public's interest in something that is shown, both verbally and non-verbally. Advertising builds a perception to encourage consumers to choose the products offered. There are many ways that the advertisers do to convince consumers, such as making interesting stories or using advertising language that sounds convincing and stunning. This statement is in line with the explanation of Sukamto and Kartikawangi (2012), they said that in a language perspective, advertising is always packaged in persuasive languages, whose purpose is to influence prospective customers to buy services or products offered (p.3). Based on the explanation above, it can be interpreted that the use of language in advertising is different from the use of language in everyday life. The language in advertising contains its own attraction which function is to directly influence the minds of those who see the advertisement. In addition to language, other elements in advertising such as images, music and other details also have a function to influence people's minds indirectly. This explanation is in accordance with the statement stated by Vellnagel (2011), "There are advertising campaigns which transfer emotions that stay in the viewers mind by attracting attention through provoking or emotional images" (p.29)

In its distribution, there are various kinds of ways to promote the advertisement to the society, as stated by Dyer (2009):

You can advertise by word of mouth, quite informally and locally, and without incurring great expense. But if you want to inform a large number of people about something, you might need to advertise in the more familiar sense of the word, by public announcement (p.2).

Mass media can be used as a means to inform advertisements to the public. Mass media is one of the communication tools that reach the wide community. Sukamto and Kartikawangi (2012) explain about the function of mass media which acts as a means of distributing advertisements, they stated that in its role as a communicating media, mass media has two functions; they are social functions and individual functions. The social functions of the mass media include: environmental supervision, correlation between parts in society to respond to their environment, socialization or value inheritance, and entertainment function. While the individual functions of the mass media include: supervision or information seeking, self concept development, facilitator in social relations, substitution in social relations, means to relieve emotions, escape from tension and alienation, and part of routine life (p.2).

At this moment, advertising is not only used to sell products or services. As stated by Onal (2005), "the purpose of advertising became more about selling an identity and a lifestyle (p.10)." According to him, at this time the use of advertising is more than just to promote a product, the advertisers, began to use advertisements to promote their identity and transfer their ideological inserted through images, music and writing of the advertisement. If we refer to ideology, it is inseparable from discourse that builds perceptions on one's mind.

Discourse as we know is not only in written form. In essence, discourse is the application of the language applied in everyday life, as described by Fairclough (1995), he stated that discourse is "language use conceived as 
social practice" (p.135). The definition above is supported by Brown and Yule (1988), they explained that if we want to analyze a discourse, it means that we not only analyze the language, but also analyze the use of the language (p.1). This explains that discourse is inseparable from social practice, which means that in its analysis, we must involve social conditions and how these discourses are used in community. Cook (2001) considered advertising as discourse. He stated that:

Although the main focus of discourse analysis is on language, it is not concerned with language alone. It also examines the context of communication: who is communicating with whom and why; in what kind of society and situation; through what medium; how different types and acts of communication evolved, and their relationship to each other (p.3).

In this article, the author wants to analyze the discourse in Shopee advertisement 12.12 birthday sale. The purpose of this analysis is to find out the purpose of why this advertisement is made and the social conditions underlying the making of the advertisement.

Shopee is an electronic commerce platform which becomes a medium for online buyers and sellers. The sellers and buyers can make transactions through the application provided on their smart phone. Currently, Shopee is one of the largest mobile shopping centers in Indonesia. In November 2018, Shopee issued an advertisement "12.12. Birthday Sale" as a form of promotion for Harbolnas (National Online Shopping Day) event which will be held on December 12 by all e-commerce platforms in Indonesia. The interesting thing about the advertisement made by Shopee is the concept of the advertisement and the selection of the actresses who are chosen to advertise and to promote their platforms. This is the reason why the writer wants to examine about the purpose about why this advertisement is made and the social conditions underlying the making of the advertisement.

\section{Related Theories}

In this article, the writer uses discourse analysis theory proposed by Norman Fairclough. He stated that "Discourse, and any specific instance of discursive practice, is seen as simultaneously (i) a language text, spoken or written, (ii) discourse practice (text production and text interpretation), (iii) sociocultural practice" (Fairclough, 1995, p.97).

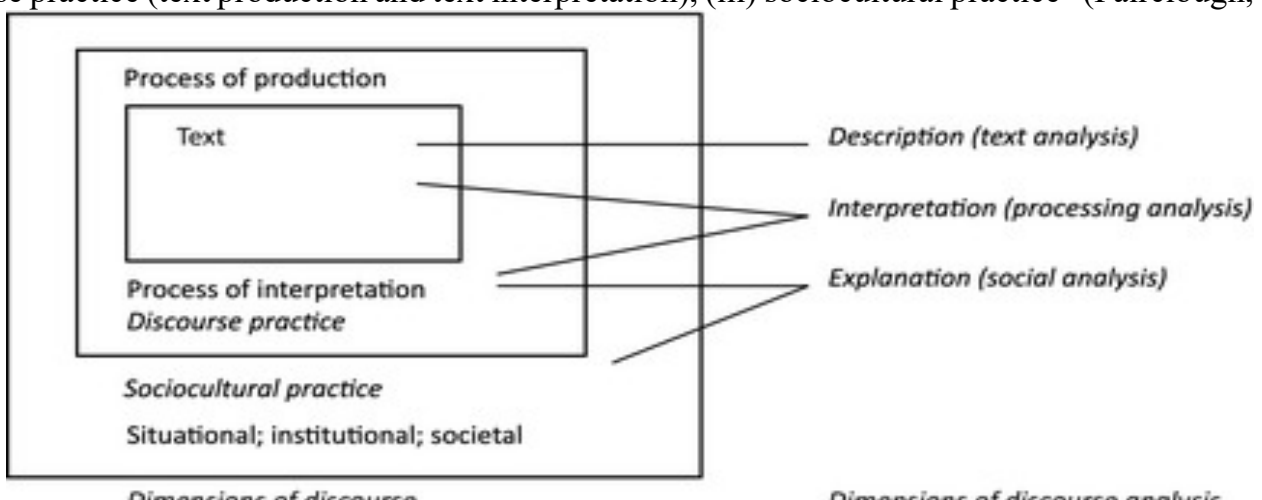

Dimensions of discourse

Dimensions of discourse analysis

Figure 1. The Three dimensions of Discourse Analysis

In addition to using Fairclough's theory, the writer also uses Wilfred's theory to support Fairclough's threedimensional theory which becomes the main theory in this article. Wilfred (1962) said that color has its own connotative meaning. Every color has different meaning to each other. The meaning of the color will be explained in table.

Table 1. The Connotative Meaning of Color

\begin{tabular}{|l|l|}
\hline Color & Connotation \\
\hline Red & $\begin{array}{l}\text { aggressiveness, activeness, strength, courage, attraction, evil, desire, revolution, anger, and } \\
\text { danger }\end{array}$ \\
\hline Dark Red & hospitality and nobility \\
\hline Dark Blue & wisdom, integrity, greatness, honesty, strength, constructivity, sincerity, and cooperation \\
\hline Light Blue & peace, youth, depression, firmness, introvert, and tenderness \\
\hline Pink & femininity, love, romance, and sympathy \\
\hline White & purity, peace, kindness, and naivety \\
\hline Black & darkness, mystery, magic, formality, and luxury \\
\hline Gray & independence, stability, criticism, and seriousness \\
\hline Brown & old age, wealth, depression, fertility and moodiness \\
\hline Green & modesty, affection, freshness, peace, youth, jealousy, poison, and mischief \\
\hline Purple & royalty, femininity, expressivity, sensitivity, youth, hope, wealth, and spiritual obsession \\
\hline Yellow & tolerance, light, speed, gold, hope, inspiration, joy, happiness, and dishonesty \\
\hline Orange & energy, warmth, activity, creativity, brightness, and hospitality \\
\hline
\end{tabular}




\section{Method}

This article applies a descriptive qualitative method. This method describes and explains the phenomenon or events in the social world, in which the writer will explore it from the point of view of the actresses and reflect on their own interpretation. The qualitative method in this article means that the result of this article is analyzed and elaborated descriptively.

The source data used in this article is a "12.12 Birthday Sale" version of the Shopee advertisement video which has 30 seconds in long. This advertisement video is taken from Instagram.com. Related to data analysis, this advertisement video is selected into 15 scenes. There are several steps or procedures in analyzing the data. First, the selected videos are carefully observed to get a comprehensive understanding. Second, each scene that has been identified is then divided into 15 scenes. Third, the scenes that have been selected are then analyzed based on Fairclough's (1995) three-dimensional theory, which includes text analysis (oral and image text, discourse practice and social practice (situational, institutional and social). Fourth, draw a conclusion regarding the purpose of this article; that is to find out the purpose about why this advertisement is made and the social conditions underlying the making of the advertisement.

\section{Discussion}

\subsection{Text Analysis}

Text is one of the important elements in a discourse. One of the most widely known text definitions is proposed by Halliday (2014), he said "...text is what listeners and readers engage with and interpret. The term 'text' refers to any instance of language, in any medium, that makes sense to someone who knows the language; we can characterize text as language functioning in context" (p.3). The text does not have to be in the form of writing, images and signs. Verbal utterance that has meaning can also be interpreted as a text, namely oral text. In this analysis, the writer will distinguish the analysis of oral text and the analysis of image text.

4.1.1Oral Text

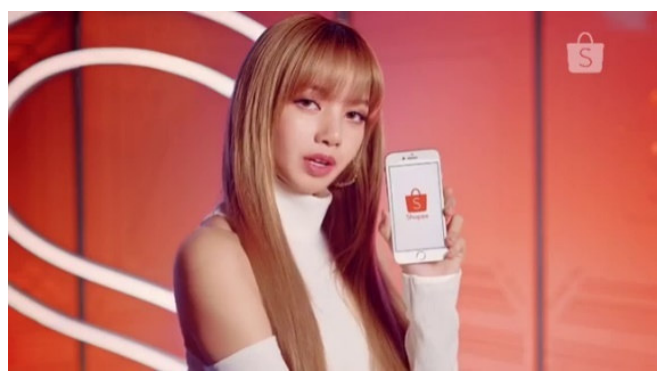

Figure 2

At the end of the advertisement, there is a scene when the actress is showing a smart phone that displays the Shopee application logo, in that scene the actress says an Indonesian phrase "Beli semua di Shopee". If the phrase is seen as a text, the phrase above does not have anything in particular, because it is only in the form of an invitation for the audience to use the Shopee application service for their buying and selling media. However, if you look at the one who says it, the phrase has a greater effect, because the phrase is spoken by a foreign artist who is currently at the peak of popularity. Even though the delivery style used by the actress is normal, but because of her status as a foreign citizen who speaks Indonesian, that is an attraction for the phrase she says.

4.1.2Image Text

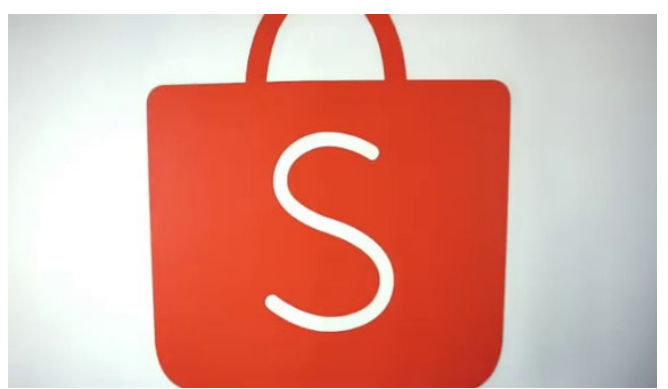

Figure 3

The advertisement begins with the appearance of the Shopee logo, the picture of the bag represents the shopping bag, the orange color represents a feeling of warmth, energy, creativity and friendliness, and the large $\mathrm{S}$ in the middle represents the first letter representing Shopee as a symbol of the company that made the advertisement. 


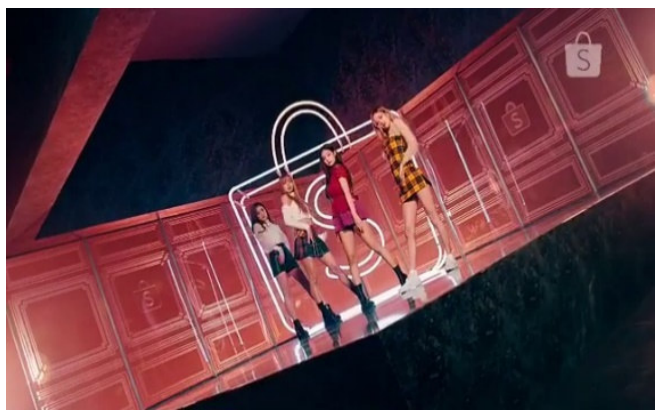

Figure 4

Next, the scene turns to the four Blackpink members who are the main point in this advertisement. The four of them stand forming the choreography formation of " $d d u d d u d d u$ " song which belongs to their latest song and becomes the background music in this advertisement.

The arrangement of the room in this scene is inspired by the music video of " $d d u d d u d d u$ " song, but in this advertisement, the background of the four Blackpink members is a Shopee logo, the brand that they had to promote.

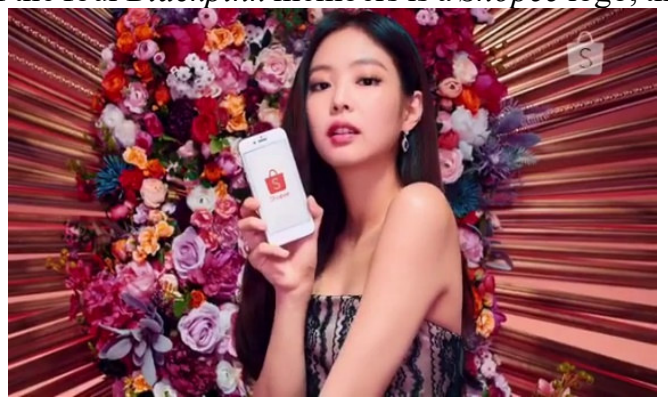

Figure 5

The next scene shows one of Blackpink members who is sitting and holding a cell phone that shows the logo of Shopee application. This picture accentuates the feminine side which can be seen from the collection of flowers that becomes the background for the scene. The facial expressions shown by the actress shows the impression of being cold and arrogant. It is indicated by the eyes that pointed down with a flat face without a smile.

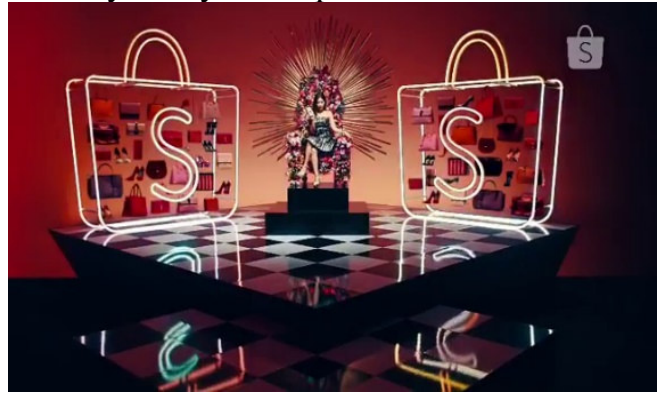

Figure 6

At this scene the picture is taken from afar. In this picture, it can be seen that there is a floor that resembles a stage. This represents the actress who has status as a singer. In addition, it can be seen that the actress sits on a throne. This shows that anyone sitting on top of the chair is a queen. It also relates to the arrogant expressions shown earlier. That expression commonly expressed by someone who has a high social status, like the queen. In addition, the magnificent impression is also seen in the picture above. The light background that is not too bright, as well as the black color on the dress and the stage floor, exudes a magical and luxurious impression.

It can be seen that beside the throne there is a giant bag with a Shopee company logo, and inside the giant bag there are many items displayed neatly. Implicitly, these two bags indicate that the consumers can buy anything they want, because the items are available at Shopee. But if you look deeper, the bag resembles a shelf for collectible items. So the items arranged in it are collectibles, which we know that people who usually collect such items are people with high financial status. So implicitly, this image indicates luxury. If consumers want a fancy style like a queen, they can get these items at Shopee. 


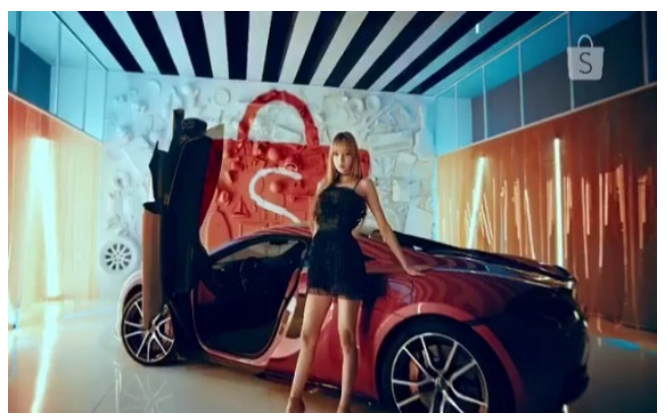

Figure 7

The next scene switches to another actress of the advertisement. It can be seen that the actress is standing next to a luxury sport car with one of the doors opened. Behind her, there is the logo of Shopee, the picture of a bag with the big letter $\mathrm{S}$ in the middle. The car in this scene identifies high social status and the color of the car means courage, attraction and desire. Besides that, the black color of the dress worn by the actress in the advertisement has the meanings of mysterious and luxury.

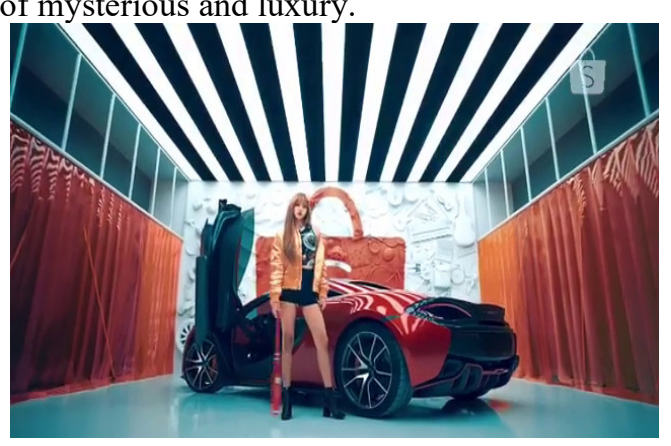

Figure 8

In this scene, the actress has the same setting as in the previous scene, but the dress she wears is different. It can be seen that the actor wears black cloth with orange jacket as an outer. In this scene, the actress stands a little farther from the car and she holds a baseball bat. The pose of standing and holding a bat signifies courage and aggression. While the color of the jacket she wears means energy. The relation between the meaning of the pose and the meaning of the orange color indicates the strong energy and bravery.

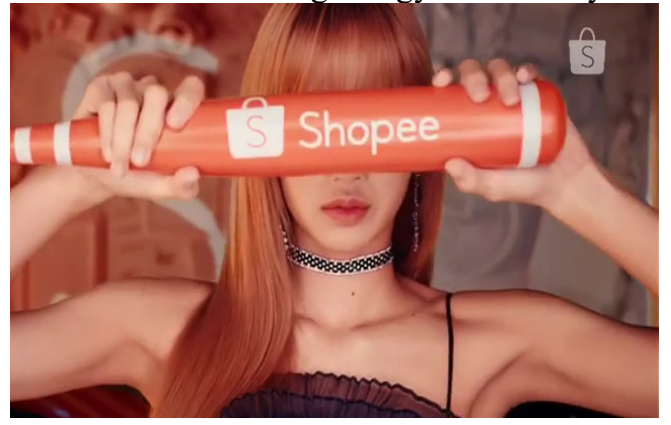

Figure 9

In this scene, the model of the advertisement raises a baseball bat with the logo and the brand Shopee to her face, covering her eyes. This gesture can be interpreted that the actress closes her eyes from other e-commerce platforms and only see and use Shopee as an e-commerce platform.

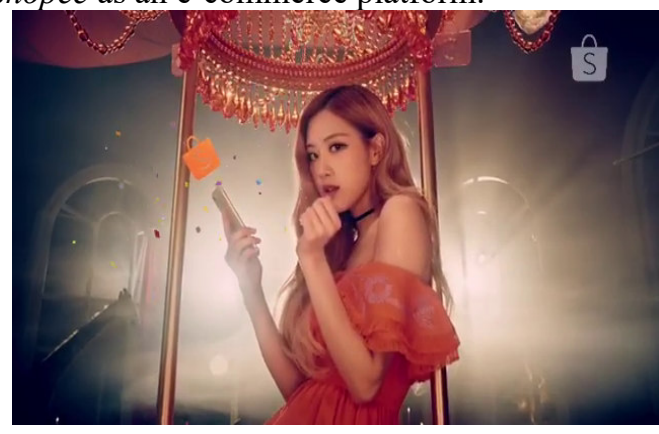

Figure 10

In this picture, the advertiser is more focused on accentuating the visuals of the model of the advertisement. 
It is clearly seen, from the way the image is taken. The purpose of this scene is; first, to attract the audience using the visuals of the actress. Although it is only a picture, this picture has an ideology. The picture shows the beauty standard of a woman. This image focuses on the visuals of the actress, who has a beautiful face and a smooth skin. This can affect the thought of the audience, so that it will be remain in their mind that the image of a beautiful woman is a woman who has beautiful appearance, smooth skin, natural makeup and a slightly cold expression. But if we associate picture with Shopee advertisement, this image acts as an opening scene that will attracts the attention of the audience to the next scene. The visual power of this scene serves to capture the attention of the audience, so that their attention is fully focused on the scene in the advertisement.

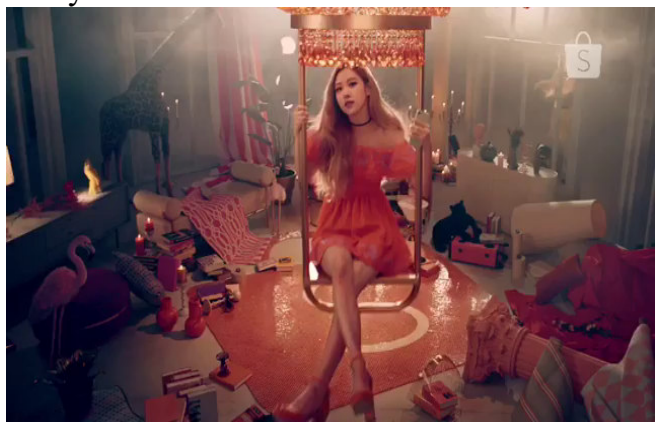

Figure 11

This scene shows the items that are being promoted by the model of the advertisement. In this scene, there is no specific classification of the product being promoted, but with a background in the form of a living room, and a messy state of the goods, it indicates that any items inside the house can be purchased on the Shopee site. The orange theme in this image represents the color of the Shopee company logo and has a meaning of warmth and creativity.

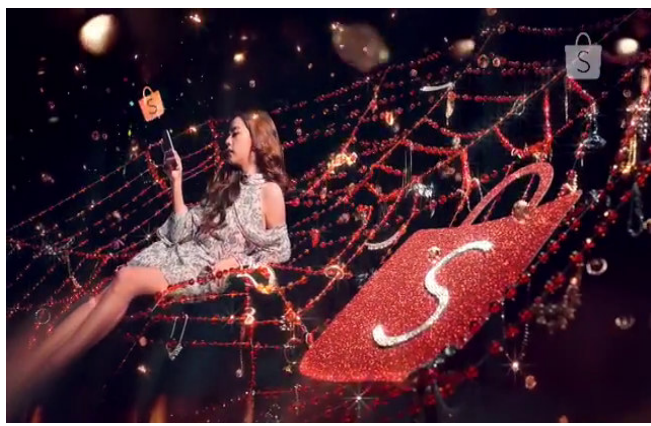

Figure 12

In this scene, the actress is sitting on a net-shaped trinket while looking at the smart phone in her hand which shows the Shopee application logo above it. In this scene, the advertiser wants to let you know that in addition to everyday items, the advertiser also provide various kinds of beautiful knick-knacks.

From the actress's pose, it is seen that she is spending time relaxing while looking at the accessories sold at Shopee. However, the image of the net there can have other interpretation, that is, the more we lulled asleep with all the offers that provided, so we unconsciously become entangled in the net they are stocking. The point is, if we are negligent and easily captivated by all the discounts or prizes offered, we might even consciously spend the money we have to buy a lot of things we don't need.

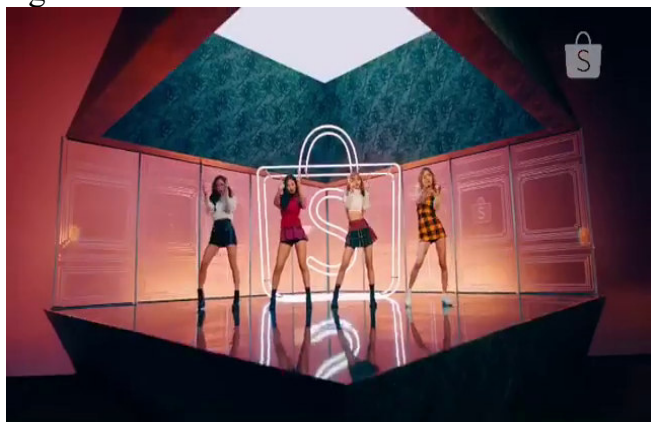

Figure 13

In this scene, the four Blackpink members who are the models in this advertisement stand forming the choreography formation of their song. This still has correlation with the Figure 4, in which the actors of the advertisement also stand forming the choreography of their song.

But at the Figure 4, they showed the beginning form of the choreography, while in this scene, they show the 
ending form of the choreography.

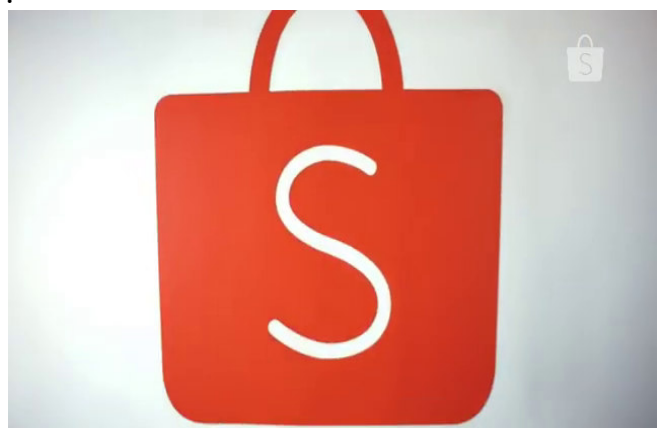

Figure 14

In this scene, the logo of Shopee reappeared as the focus of the advertisement. The Shopee logo appears at the beginning and at this scene by acting as a gate. At the beginning of the advertisement, the Shopee logo represents the opening gate, while at this scene the logo represents the closing gate.

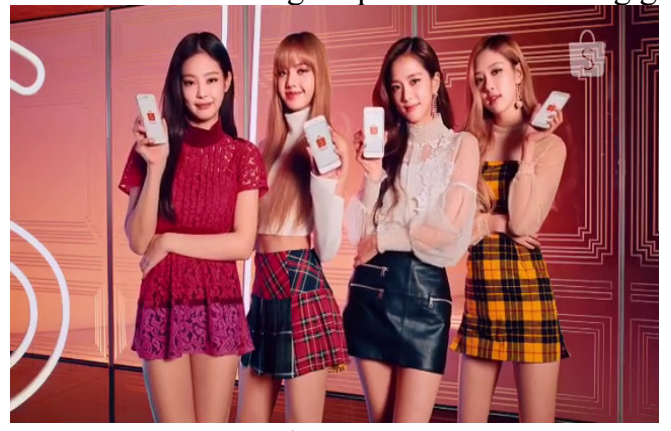

Figure 15

The advertisement was closed with the four Blackpink members standing side by side showing a smart phone in their hands that showed the Shopee company logo. The purpose of this scene is clearly to promote the Shopee application to the entire audience. With sweet and smiling facial expressions that show their beautiful sides, the models of this advertisement show Shopee's company logo, and this gesture can be understood that they inviting all viewers to download the applications shown, and use it.

In this scene, it can be seen that the producers of the advertisements are highlighting the physical advantages of the actresses, which indicates the standard of beauty for most women in Indonesia. Beautiful face, smooth skin, white, slim body, long legs, all these things are shown by the advertisers in this scene. Here is the attraction of the famous Korean girl groups which is not owned by most Indonesian artists. This is the plus point for Shopee companies compared to other online companies that are engaged in the same field which but do not make Korean artists as their advertising stars.

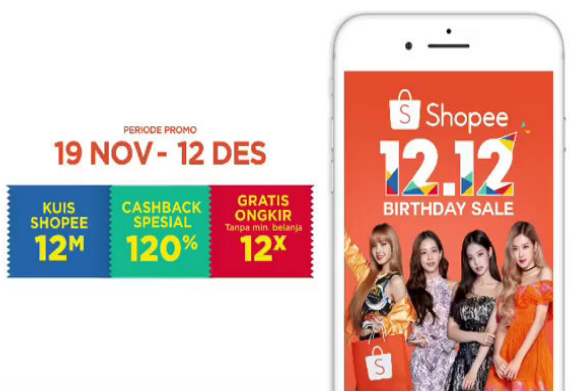

Figure 16

This last scene shows the date regarding the promos offered by the advertiser. You could say that the essence of Shopee "12.12. Birthday Sale" advertisement can be found in this scene, because this scene contains information about events and promotions which becomes the core of the advertisement. This scene is intentionally placed at the end of the advertisement, so that the information contained in this scene can be conveyed properly, and the information can be absorbed in the audience's mind.

\subsection{Discourse Practice}

In this section, the analysis is focused on how text is produced and consumed. According to Fairclough, there are two sides to this practice, namely the production of text (on the media) and consumption of text (on the public). This advertisement adapts the concept of music video which belongs to the models of the advertisement, a Korean 
girl group named Blackpink. The advertiser displays scenes which becomes the highlight of the music video, so that the audience feels interested and familiar with the advertisements displayed. Most advertisements use illustrations with background music, which is one of the hits song from girl group Blackpink. The absence of written text in this advertisement aims at making the audience more focused on the scenes provided by the advertiser. This advertisement is then disseminated through various media, including electronic mass media and social media.

If the advertisement is seen from the side of the people who consumes the advertisement, this advertisement is intended for all people; from adolescents, adults, men, women, middle class and upper class. In general, the public understands the purpose of this advertisement, which is to invite consumers to buy products through applications provided by advertisers and invite sellers to become business partners by offering their products through Shopee online companies.

\subsection{Social Practice}

\subsubsection{Situational}

Every text generally refers to an ongoing event. Or in other words, situational aspect looks more at the context of events that occur when the discourse is made. The advertisement of Shopee "12.12 Birthday Sale" is created during the national online shopping in Indonesia. Indonesian people recognize the phrase "good date (tanggal cantik)", in which the date and month have the same number. In addition, the end of the year is a common time for sellers to offer their products by luring large discounts for consumers. This is the background of the existence of national online shopping in Indonesia, when online stores offer a variety of products with various price discounts. This event is widely used by online sellers to make advertisements as attractive as possible, so that the consumers feel interested in these advertisements by using the artist who is famous and admired by the community. One of them is the Shopee online platform that uses Blackpink to become their advertising model as well as their brand ambassadors. The reason for choosing Korean girl group Blackpink as the advertising model is because nowadays, girl group Blackpink is at their peak of popularity. There are many people who know and admire them. Not only in Indonesia, in other countries, Blackpink's popularity has become widely known. So that by making them as the advertising actor as well as brand ambassadors, it is expected that fans or the wider community who are stunned by their charm will use the services of advertising companies and increase the sales of products provided in their application.

\subsubsection{Institutional}

Institutional sees how exactly the influence of an organization institution, in practice when a discourse is produced. This advertisement affects the viewers and consumers, because these advertisements are produced by a big and well-known institution in the society. If the advertisement comes from a big and well-known company, the grater the influence it gives to the society. In this article, Shopee is the institution which makes the advertisement. In Indonesia, Shopee is one of the well-known online shopping centers, so the influence and ideology conveyed in the discourse on this advertisement will spread wider and easier.

4.3.3 Social

The social aspect looks more at the micro aspects such as the economic system, the political system, or the whole cultural system of society. In this advertisement, discourse is made based on the consumptive culture of Indonesian society. The increasing level of consumption of goods among the public provides an opportunity for sellers to attract more consumers. At this, Indonesians prefer to buy products that are having a promo, regardless of whether they really need it or not. The nature of this hedonism is used by advertisers to attract more consumers to buy and use their services as online shopping centers. The lure of large discounts is an effective trick to attract the interest of the target market.

In addition, at this time many foreign cultures enter Indonesian society, like western and Korean culture. These cultures enter Indonesia through various means, such as music and fashion. Many Indonesians, especially the younger generation consider Korea as the center of trends. It makes any product related to Korean will be in great demand by the millennial generation of Indonesia. This phenomenon is then used by the advertisers, to use Korean artists as the advertising model as well as their brand ambassadors, so that the people who love Korean culture will buy the products they offer.

The two things above are related to each other, in which by adjusting the tastes and styles of the people who are currently liking Korean culture, then by displaying Korean artists that they admire, the audience of the advertisement will be more consumptive in spending their money to buy the product offered by the advertiser.

\section{Conclusion}

In the previous section, it has been described and explained about the discourse analysis contained in Shopee "12.12. Birthday Sale" advertisement. Based on the discussion above, it can be concluded that discourse is not only about text. Discourse includes the use of language, social conditions and other elements incorporated in one unit. In this article, the elements that build the discourse above are text, images, situational aspects, institutional 
aspects and social aspects.

Every discourse has its own purpose. The purpose of this advertisement is of course to introduce their products and brands to the society. But, besides to advertise their products, Shopee also advertises their identity as a company which follows the trend and can comply with the consumer wishes. Through this advertisement, Shopee wants to show that Shopee will not disappoint their customers, because they provide a variety of goods needed by the community. In addition, Shopee also wants to inform that there are many benefits that consumers will get, such as discounts and collaborating with famous artists who are popular in the public.

The social conditions behind the creation of these advertisements are the increasing level of consumer consumption and the existence of national online shopping events in Indonesia. In addition, at this time Indonesian people are fond of Korean music, style and culture. This is the main reason why Shopee makes Korean artists as their advertising model and brand Ambassador, because Korean artists have more attraction if they are compared to local artists. This is very beneficial for e-commerce platform like Shopee to attract their target consumers.

\section{References}

Brown, G. \& Yule, G. 1988. Discourse Analysis. Cambridge: Cambridge University Press.

Cook, G. 2001. The Discourse of Advertising. New York: Routledge.

Dyer, G. 2009. Advertising as Communication. London: Routledge.

Fairclough, N. 1995. Critical Discourse Analysis: The Critical Study of Language. New York: Longman Group Limited.

Halliday, M.A.K. 2014. Halliday's Introduction to Functional Grammar. New York: Routledge.

Onal, B. 2005. Subvertising Versus Advertising: A Semiotical Analysis of the Culture Jamming Act. Thesis. Bilkent University, Ankara, Turkey.

Sukamto, K. E. dan Kartikawangi. D. 2012. "Bahasa iklan dan pemberdayaan perempuan: Sebuah kajian komunikasi dan bahasa terhadap iklan tv produk 'citra'. "Ranah, 1 (2), hlm. 1-13. DOI: https://doi.org/10.26499/rnh.v1i2.3

Vellnagel, C.C. 2011. Semiotic and Shock advertisement. Norderstedt Germany: GRIN Verlag.

Wilfred, T. (1962). “Color Organ”. In Comton's pictured encyclopedia (pp. 235-237). Chicago: F.E. Compton and Company. 